\title{
- Dural Arteriovenous Fistula-Derived Rase Parkinsonism Symptoms: A Case Report with Literature Review
}

Atsushi Tominaga, Yoshinori Kiura, Hiroshi Kondo, Shinichiro Takeshita, Takuro Magaki, Tetsuhiko Sakoguchi, Yuyo Maeda, Yusuke Takeishi, Sayuru Tsuyuguchi, and Daijo Shiota

Objective: Parkinsonism caused by dural arteriovenous fistula (DAVF) is very rare, however, it is reversible by endovascular treatment. We herein report a case of parkinsonism caused by DAVF with review of previous literature.

Case Presentation: An 87-year-old woman with parkinsonism and dementia was admitted to our hospital with disturbance of consciousness and aggravated parkinsonism symptoms. Plain CT revealed low-density areas in the brainstem and left cerebellar peduncle. Magnetic resonance images revealed hyperintense lesions on FLAIR, which had elevated apparent diffusion coefficient (ADC) values, in the same lesion of plain CT. However, no edematous change was detected. CT angiograms revealed obstruction of the left transverse and sigmoid sinuses. Dilations of the left superior petrosal sinus, left petrosal vein, and pontine veins were also noted. A low-density area on plain CT had a contrast effect. Cerebral angiography revealed a DAVF involving the left transverse sinus and fed by the left occipital and left middle meningeal arteries. Transarterial embolization (TAE) with Onyx obliterated the DAVF, and parkinsonism symptoms gradually improved. We reviewed 21 DAVF-derived parkinsonism cases, most of which were treated by TAE. Recent cases were treated with Onyx. In many cases, parkinsonism improved after endovascular treatment.

Conclusion: DAVF-derived parkinsonism is rare but treatable by endovascular therapy. DAVF should be one of the differential diagnosis of the parkinsonisms.

Keywords > dural arteriovenous fistula, parkinsonism, transarterial endovascular treatment, dementia, Onyx

\section{Introduction}

Parkinsonism is caused by brain degenerations and irreversible in most cases. The drug-induced parkinsonism is well known and reversible by discontinuation of the drug. Very rarely, reversible parkinsonism was reported to be caused by the deep-vein thrombosis and dural arteriovenous fistula (DAVF). ${ }^{1}$ DAVF is an arteriovenous (AV) shunt of the dura mater and causes various symptoms due to venous

Department of Neurosurgery and Neuroendovascular Treatment, Hiroshima Prefectural Hospital, Hiroshima, Hiroshima, Japan

Received: April 15, 2021; Accepted: July 16, 2021

Corresponding author: Atsushi Tominaga. Department of Neurosurgery and Neuroendovascular Treatment, Hiroshima Prefectural Hospital, 1-5-54, Ujinakanda, Minami-ku, Hiroshima, Hiroshima 734-8530, Japan

Email: Tominaga-hma@umin.ac.jp

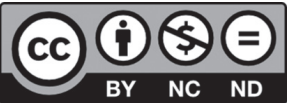

This work is licensed under a Creative Commons Attribution-NonCommercialNoDerivatives International License.

(C)2021 The Japanese Society for Neuroendovascular Therapy congestion of the intracranial venous system. ${ }^{2)}$ Parkinsonism is one of the symptoms of DAVF; however, it is extremely rare and difficult to diagnose. To the best of our knowledge, only 21 cases have been reported. We herein report a case of DAVF-derived parkinsonism with review of past literatures.

\section{Case Presentation}

An 87-year-old woman presented with memory disturbance and depression for one year. Neurological examination revealed the signs of parkinsonism including rigidity, bradykinesia, and tremor. MRI revealed a preexisting infarction, brain atrophy, and age-appropriated degenerative white matter. The patient was diagnosed with Parkinson's disease and L-dopa was given. The patient's rigidity improved after medication. One year later, the symptom of rigidity recurred with aggravating gait disturbance and difficulty of eating. The patient finally developed disturbance of consciousness and was referred to our hospital. On admission, she was somnolent, with no motor paralysis; however, the rigidity was noted in all extremities. A blood test revealed elevation of fibrin 

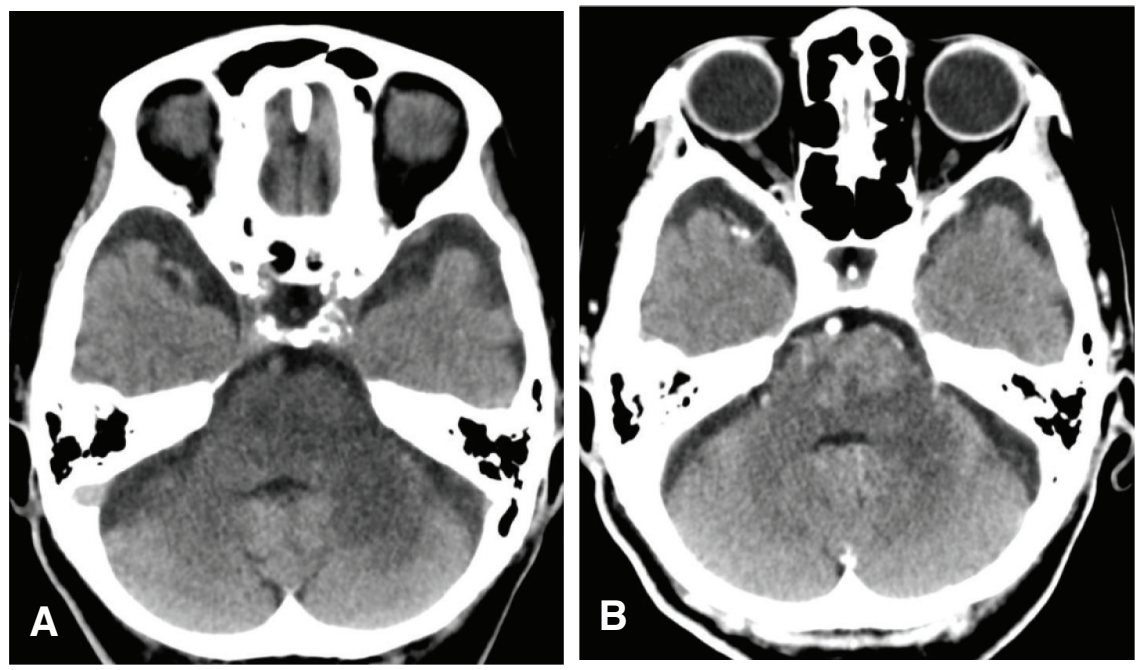

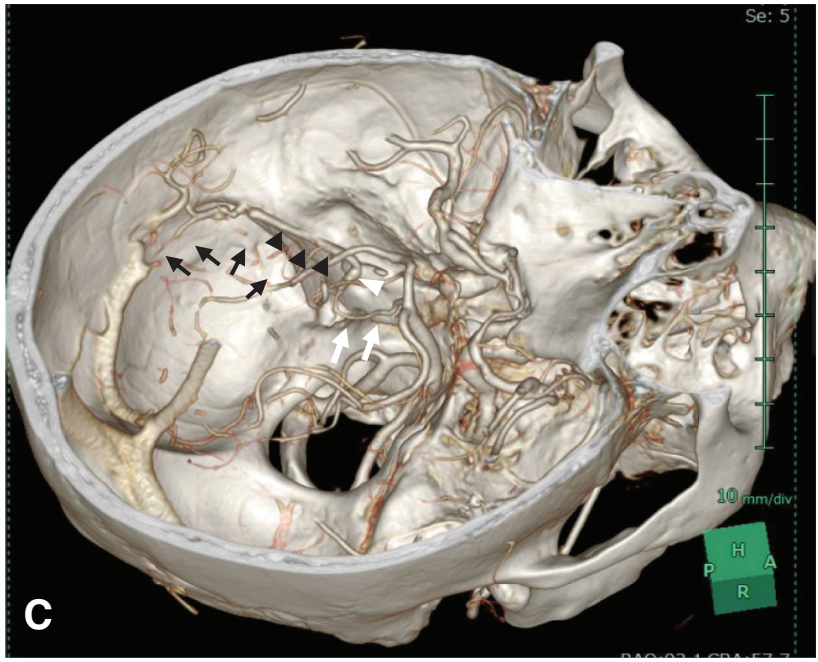

Fig. 1 CT on admission. (A) Plain CT, (B) enhanced CT, and (C and D) CT angiograms. Plain CT (A) shows low-density areas in the brainstem and the left cerebellar peduncle. Enhanced CT (B) shows a slight enhancement effect of the low density area in the plain CT. Notice the dilated pontine veins. CT angiograms (C and $\mathbf{D})$ show

degradation products (FDP) $(7.0 \mu \mathrm{g} / \mathrm{ml})$ and $\mathrm{D}$ dimer $(2.6 \mu \mathrm{g} / \mathrm{ml})$. Head plain CT (Fig. 1A) revealed diffuse low-density areas in the brainstem and left cerebellar peduncle. Head MRI (Fig. 2) showed high-signal intensity changes in the same lesions as plain CT. The ADC values of these areas were increased. A high-signal intensity spot in the left basal ganglia was recognized on a FLAIR image (preexisting lesion observed one year before investigation), as diagnosed an old lacunar infarction. No edematous change was shown in the bilateral cerebrum hemispheres (including the thalamus). The left superior petrosal vein was recognized as a high-signal intensity area on the arterial phase of MRA. These findings were not recognized on the MR angiogram one year ago. DAVF was suspected and followed with enhanced CT and CTA. In the brainstem and left cerebellar peduncle, the

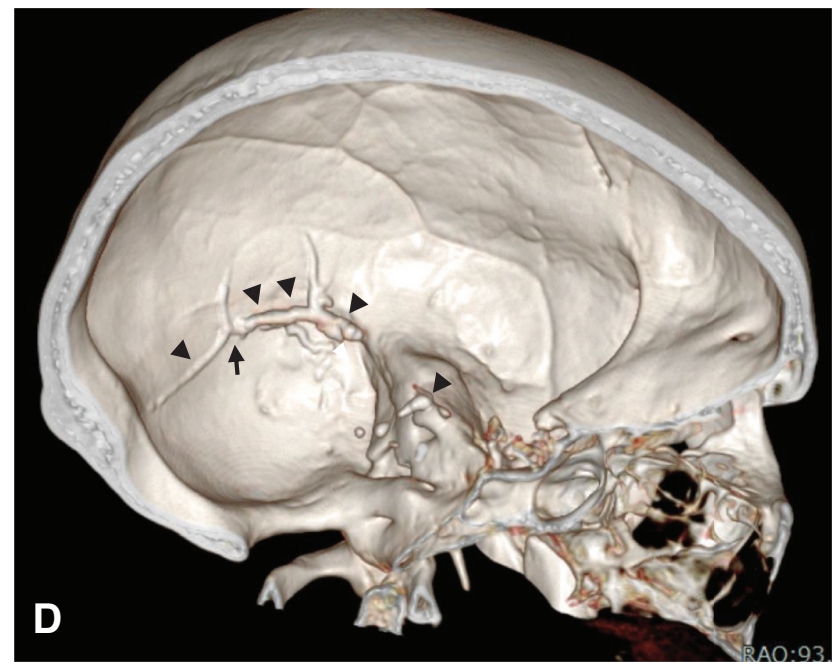

obstructions of the lateral side of the left transverse sinus and the left sigmoid sinus (black arrows). The left superior petrosal sinus (black arrowheads), the dilated petrosal vein (white arrowhead), and the pontine veins (white arrows) are well visualized.

low-density lesion on plain CT was slightly enhanced with contrast media revealing a dilated pontine veins (Fig. 1B). CTA demonstrated the dilations of the left superior petrosal sinus, left petrosal vein, and pontine veins, with obstruction of the left sigmoid sinus (Fig. 1C and 1D). Left common carotid angiogram showed the DAVF located at the anterolateral edge of the tentorium cerebelli with occlusion of the left sigmoid sinus from the transverse-sigmoid junction. It was fed by the left occipital and left middle meningeal artery (MMA), and was directly drained into the left superior petrosal sinus (SPS). The shunt flow finally refluxed into pontine and cerebellar veins via the left petrosal vein (Borden Type III) (Fig. $\mathbf{3 A}$ and $\mathbf{3 B}$ ). In the late arterial phase, the contrast medium was distributed throughout the cerebrum (Fig. 3C and 3D). In the venous phase, the internal cerebral vein, straight sinus, 

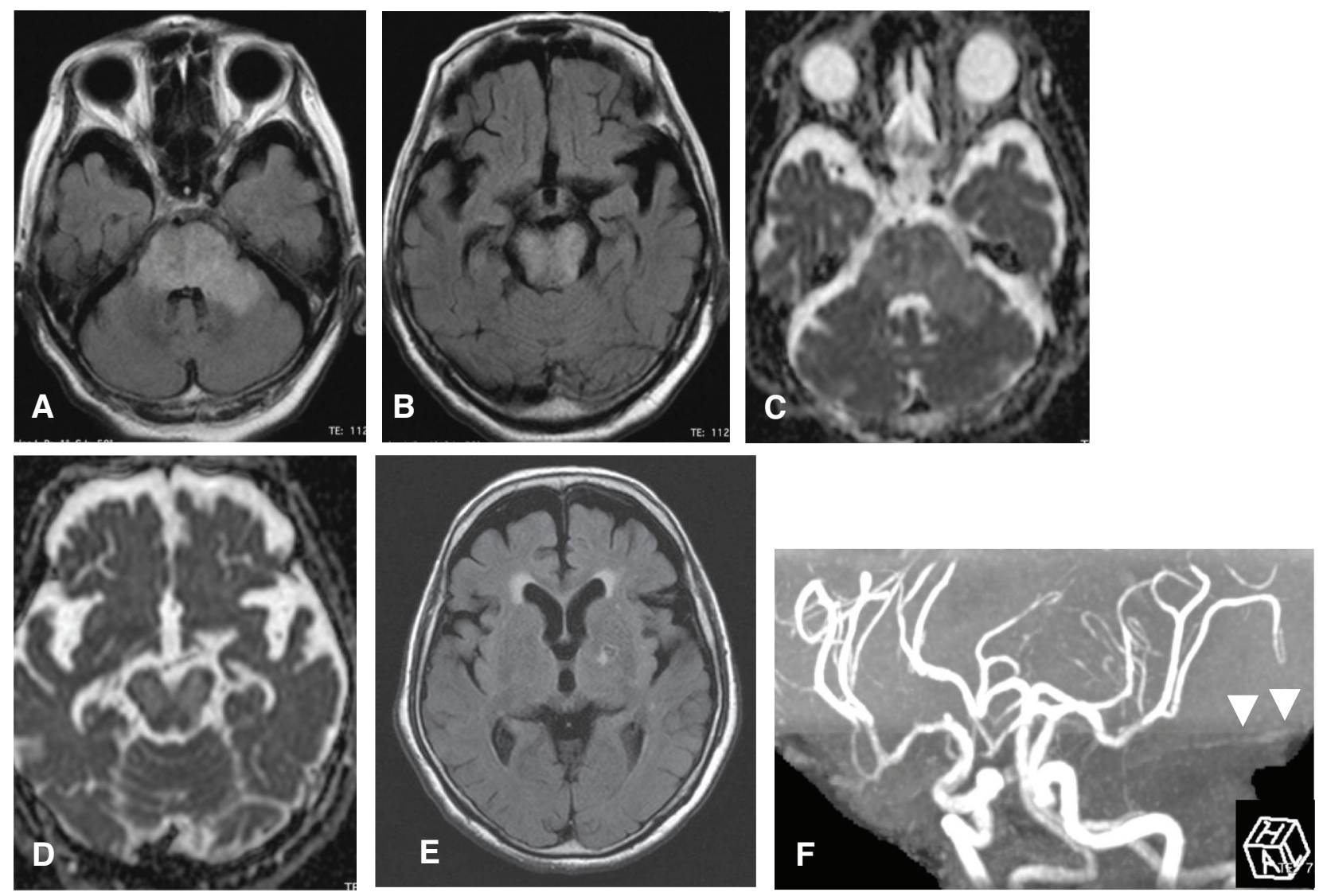

Fig. 2 MRI on admission. (A, B, and E): FLAIR, (C and D), ADC map, and (F) MRA. MRI FLAIR imaging shows a hyper-intensity area in the brainstem and the left cerebellar peduncle (A and $\mathbf{B})$. The ADC value of these area is elevated (C and D). FLAIR image shows a spotty high-intensity area in the left basal ganglia (E). The left superior petrosal sinus (arrowheads) is shown in MRA (F). ADC: apparent diffusion coefficient and superior sagittal sinus were demonstrated with no retention (Fig. 3E and 3F).

\section{Endovascular treatment}

Transarterial embolization (TAE) was performed under local anesthesia: a 7-Fr long sheath (Medikit, Tokyo, Japan) was placed in the right femoral artery. After heparinization, a 7-Fr Roadmaster (Goodman, Aichi, Japan), 5-Fr JB2 (Medikit), and Radifocus Guidewire (Terumo, Tokyo, Japan) were navigated to the left external carotid artery. The left external carotid angiogram again revealed the DAVF adjacent to the left transverse-sigmoid junction, fed by a branch of the left occipital artery and posterior convexity branch of the left MMA (Fig. 4A). A 4-Fr Cerulean (Medikit) and Marathon (Medtronic, Minneapolis, MN, USA) were navigated into the main feeding posterior convexity branch of the MMA (Fig. 4B). Onyx-18 (0.27 ml; Medtronic) was injected gradually using the plug and push method, penetrating into the left SPS sufficiently (Fig. 4C), and completely obliterated the fistula (Fig. 4D).

\section{Postoperative course}

The disturbance of consciousness improved, and the patient was able to eat one week after treatment. The rigidity of extremities gradually improved and the patient was able to walk one month after treatment. L-dopa was no longer required for subsequent treatment of parkinsonism. Three months later, FLAIR image revealed no edematous lesions in the brainstem and left cerebellar peduncle (Fig. 5A and 5B). The hyperintensity spot of the left basal ganglia and the ischemic changes in the deep white matter did not change (Fig. 5C).

\section{Discussion}

DAVF-derived parkinsonism is rare, with only 21 cases reported in the past literature (Table 1). ${ }^{1,3-17)}$ Many are reported from Asia, and most of the patients were men. The symptoms of parkinsonism caused by DAVF are rigidity in most cases and tremor is observed in approximately half of the affected patients. The difference from normal Parkinson's disease is that the DAVF-derived parkinsonism is 

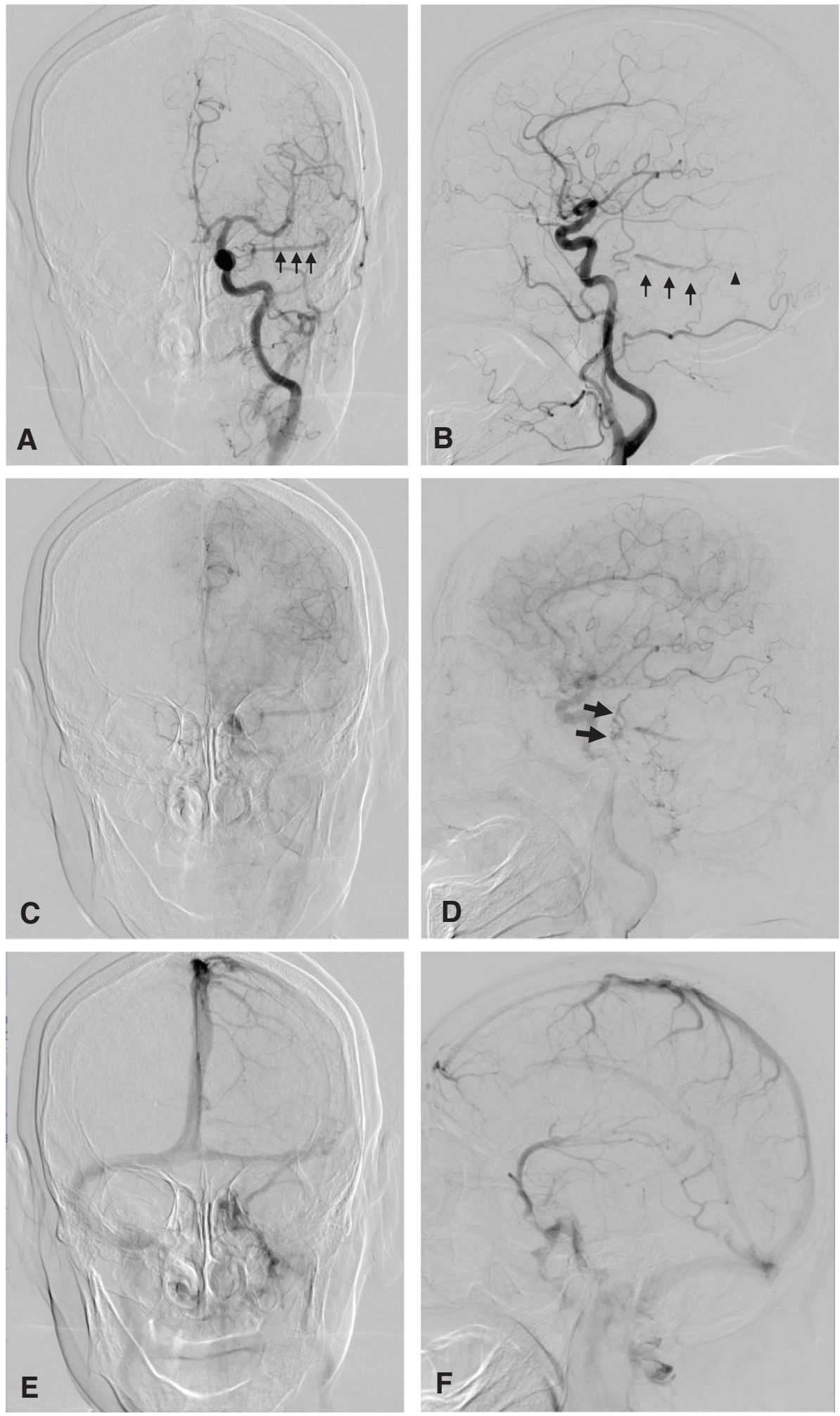

Fig. 3 Left common carotid angiograms. Common carotid angiograms show early venous filling of the left superior petrosal sinus (arrows) in the arterial phase (A and $\mathbf{B})$. The DAVF is demonstrated in the adjacent area to the left transversesigmoid junction (arrowhead), which is fed by the left occipital artery and left MMA (A and $\mathbf{B}$ ). It drains into the left superior petrosal sinus via the left sigmoid sinus. The venous reflux into the petrosal vein and the venous stasis around the brainstem (arrows) are observed (C and D). At the venous phase, the left sigmoid sinus is occluded. The internal cerebral vein, straight sinus, and superior sagittal sinus are draining with no retention ( $E$ and $F$ ). DAVF: dural arteriovenous fistula; MMA: middle meningeal artery

often associated with dementia. When encountered with a parkinsonian patient with dementia, we need to recognize the DAVF-derived parkinsonism as a differential diagnosis. The etiological origin of DAVF-derived parkinsonism is difficult to diagnose, and the period from onset to diagnosis ranges from approximately one month to several years. In most cases, draining veins of the DAVF are the superior sagittal sinus $(n=13)$, transverse sinus $(n=13)$, 

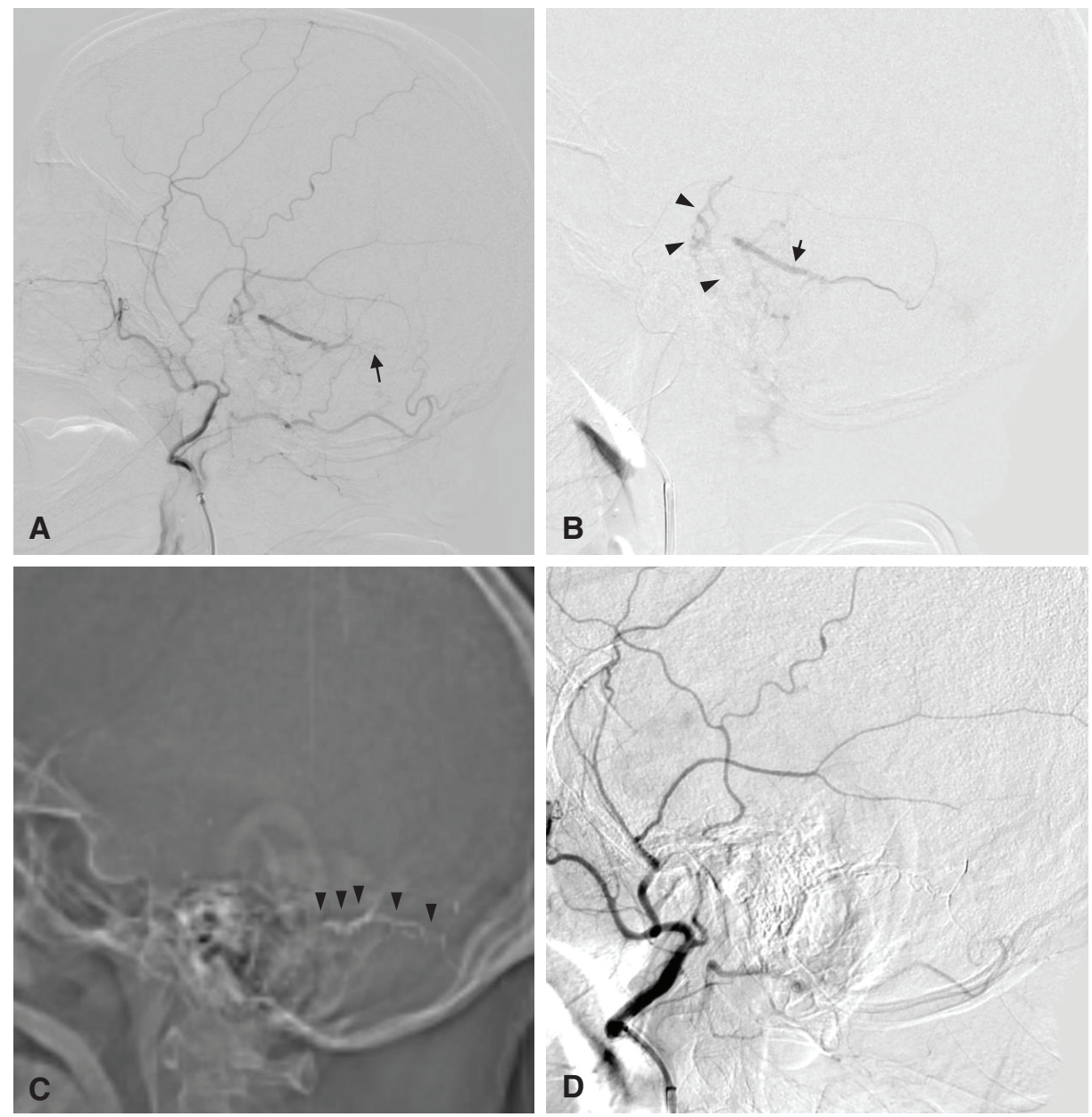

Fig. 4 Left external carotid angiogram. The left external carotid angiogram shows a DAVF (arrow) adjacent to the left transverse-sigmoid junction, which is fed by a branch of the left OA and posterior convexity branch of the left MMA (A). A selective angiogram shows the DAVF draining from the left transverse-sigmoid junction into the left superior petrosal sinus (arrow). The venous flow refluxes into the petrosal vein and dilated pontine veins (arrowheads) (B). An Onyx cast (arrowheads) is seen in the left superior petrosal sinus (C). The external carotid angiogram after treatment shows the complete obliteration of the DAVF (D). DAVF: dural arteriovenous fistula; MMA: middle meningeal artery; OA: occipital artery
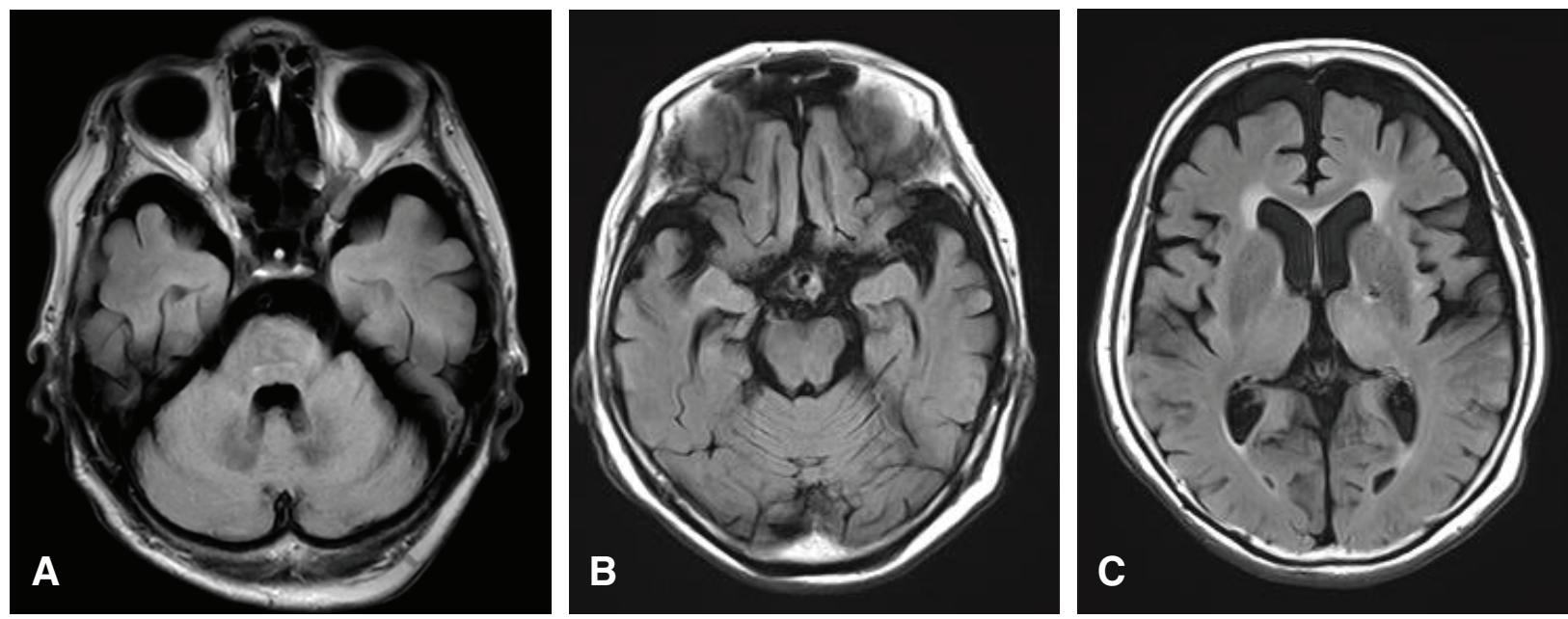

Fig. 5 Posttreatment MRI. FLAIR images of MRI show the edematous changes of the brainstem and left cerebellar peduncle disappeared (A and $\mathbf{B})$. The hyperintensity spot of the left basal ganglia remained as a preexisting lacunar infarct lesion (C). 
Table 1 Summary of the previous reports

\begin{tabular}{|c|c|c|c|c|c|c|c|c|c|c|c|c|c|c|c|c|c|c|}
\hline Author & Year & Age & Sex & Tinnitus & Bruit & Tremor & Rigidity & $\begin{array}{l}\text { Gait } \\
\text { dist }\end{array}$ & Dementia & $\begin{array}{l}\text { Time } \\
\text { from } \\
\text { onset }\end{array}$ & $\begin{array}{c}\text { Edema } \\
\text { sign on } \\
\mathrm{MRI}\end{array}$ & $\begin{array}{c}\text { CBF } \\
\text { reduction } \\
\text { on SPECT }\end{array}$ & $\begin{array}{l}\text { Region } \\
\text { of DAVF }\end{array}$ & $\begin{array}{l}\text { Venous } \\
\text { reflux }\end{array}$ & $\begin{array}{l}\text { Isolated } \\
\text { sinus }\end{array}$ & Treatment & $\begin{array}{l}\text { Embolic } \\
\text { material }\end{array}$ & Outcome \\
\hline $\begin{array}{l}\text { Matsuda } \\
\text { et al. }{ }^{3)}\end{array}$ & 1999 & 55 & M & & & $(-)$ & $(+)$ & $(+)$ & $(+)$ & $8 m$ & $\begin{array}{l}\text { BGG, } \\
\text { WM }\end{array}$ & $(+)$ & $\begin{array}{l}\text { SiS, } \\
\text { SSS, } \\
\text { StS }\end{array}$ & NR & $(+)$ & TAE, TAE & NR & Improved \\
\hline $\begin{array}{l}\text { Matsuda } \\
\text { et al. }{ }^{3)}\end{array}$ & 1999 & 78 & M & & $(-)$ & $(-)$ & $(+)$ & $(+)$ & $(+)$ & $9 \mathrm{~m}$ & NL & $(+)$ & $\begin{array}{l}\text { SiS, } \\
\text { SSS, } \\
\text { StS }\end{array}$ & NR & $(-)$ & TAE & NR & Improved \\
\hline $\begin{array}{l}\text { Matsuda } \\
\text { et al. }{ }^{3)}\end{array}$ & 1999 & 69 & $\mathrm{~F}$ & $(+)$ & & $(-)$ & $(+)$ & $(+)$ & $(+)$ & $\begin{array}{c}\text { Several } \\
y\end{array}$ & WM & & $\begin{array}{l}\text { SiS, TS, } \\
\text { SSS, } \\
\text { StS }\end{array}$ & StS & $(-)$ & TAE & NR & Unimproved \\
\hline $\begin{array}{l}\text { Hamada } \\
\text { et al. }{ }^{4)}\end{array}$ & 2003 & 44 & $M$ & & & $(-)$ & $(-)$ & $(+)$ & $(-)$ & $1 \mathrm{w}$ & NL & $(+)$ & $\begin{array}{l}\text { ant. } \\
\text { cranial } \\
\text { fossa }\end{array}$ & NR & $(-)$ & Surgery & & Improved \\
\hline Lee et al.5) & 2005 & 60 & $\mathrm{~F}$ & & & $(+)$ & $(+)$ & $(+)$ & $(+)$ & $18 \mathrm{~m}$ & WM & $(+)$ & $\begin{array}{l}\text { TS, SSS } \\
\text { StS }\end{array}$ & $\begin{array}{l}\text { SSS, ICV, } \\
\text { cortical V }\end{array}$ & $(-)$ & TAE & NR & Unimproved \\
\hline $\begin{array}{l}\text { Kajitani } \\
\text { et al. }{ }^{6)}\end{array}$ & 2007 & 75 & M & & & $(+)$ & $(+)$ & $(+)$ & $(+)$ & $14 w$ & NL & & SSS, TS & $\begin{array}{l}\text { Cortical } \\
\text { veins }\end{array}$ & $(+)$ & $\begin{array}{c}\text { TAE, } \\
\text { surgery, } \\
\text { TAE }\end{array}$ & NR & Improved \\
\hline $\begin{array}{l}\text { Miura } \\
\text { et al. } 7 \text { ) }\end{array}$ & 2009 & 65 & M & $(+)$ & & $(-)$ & $(+)$ & $(+)$ & $(+)$ & $11 \mathrm{~m}$ & $\begin{array}{l}\text { BGG, } \\
\text { WM }\end{array}$ & $(+)$ & $\begin{array}{c}\text { TS, SSS, } \\
\text { StS }\end{array}$ & StS, ICV & $(-)$ & TAEx3 & NR & Improved \\
\hline $\begin{array}{l}\text { Nogueira } \\
\text { et al.8) }\end{array}$ & 2009 & 79 & M & $(+)$ & $(+)$ & $(+)$ & $(+)$ & $(+)$ & $(-)$ & $2 y$ & NL & & $\begin{array}{l}\text { TS, SSS, } \\
\text { StS }\end{array}$ & $\begin{array}{l}\text { SSS, StS, } \\
\text { Rosenthal }\end{array}$ & $(-)$ & $\begin{array}{l}\text { TAEx2, } \\
\text { TVE }\end{array}$ & $\begin{array}{c}\text { Cyanoacrylate, } \\
\text { coil }\end{array}$ & Normalized \\
\hline $\begin{array}{l}\text { Netravathi } \\
\left.\text { et al. }{ }^{9}\right)\end{array}$ & 2011 & 54 & M & $(+)$ & $(+)$ & $(+)$ & $(+)$ & $(+)$ & $(+)$ & $3 y$ & $\begin{array}{l}\text { Thal, } \\
\text { GP }\end{array}$ & & TS, StS & StS, ICV & $(+)$ & TAE & Onyx & $\begin{array}{l}\text { Minimal } \\
\text { change }\end{array}$ \\
\hline $\begin{array}{l}\text { Netravathi } \\
\left.\text { et al. }{ }^{9}\right)\end{array}$ & 2011 & 40 & M & & & $(-)$ & $(+)$ & $(-)$ & $(+)$ & $3 \mathrm{~m}$ & NR & & SSS & $\begin{array}{l}\text { SSS, } \\
\text { Trolard }\end{array}$ & $(-)$ & TVE, TAE & Failure & Unchanged \\
\hline $\begin{array}{l}\text { Shahar } \\
\text { et al. }{ }^{10)}\end{array}$ & 2012 & 59 & M & & & $(+)$ & $(+)$ & $(+)$ & $(+)$ & $3 \mathrm{~m}$ & GP & & StS & $\begin{array}{c}\text { ICV, } \\
\text { Rosenthal }\end{array}$ & $(+)$ & TAE & Onyx & Improved \\
\hline $\begin{array}{l}\text { Hattori } \\
\text { et al. }{ }^{11)}\end{array}$ & 2013 & 52 & $\mathrm{~F}$ & $(+)$ & $(+)$ & $(-)$ & $(-)$ & $(+)$ & $(+)$ & $3 \mathrm{~m}$ & $\begin{array}{l}\text { BGG, } \\
\text { WM }\end{array}$ & $(+)$ & $\begin{array}{c}\text { TS, SSS, } \\
\text { StS }\end{array}$ & $\begin{array}{c}\text { StS, } \\
\text { cortical } \\
\text { veins }\end{array}$ & $(-)$ & TVE & Coil & Improved \\
\hline $\begin{array}{l}\text { Fujii } \\
\text { et al. }{ }^{12)}\end{array}$ & 2014 & 69 & M & & & $(+)$ & $(+)$ & $(+)$ & $(+)$ & $2 y$ & NL & $(+)$ & SSS & $\begin{array}{l}\text { Cortical } \\
\text { veins }\end{array}$ & $(-)$ & TVE & Coil & Improved \\
\hline $\begin{array}{l}\text { Luo } \\
\text { et al. }{ }^{13)}\end{array}$ & 2014 & 54 & M & & & $(-)$ & $(-)$ & $(+)$ & $(+)$ & $10 \mathrm{~m}$ & NL & & TS, SiS & NR & $(-)$ & $\begin{array}{c}\text { No } \\
\text { treatment }\end{array}$ & & No change \\
\hline $\begin{array}{l}\text { Luo } \\
\text { et al. }{ }^{13)}\end{array}$ & 2014 & 75 & M & & & $(+)$ & $(-)$ & $(+)$ & $(+)$ & $3 y$ & NL & & TS, SiS & Labbe & $(-)$ & $\begin{array}{c}\text { No } \\
\text { treatment }\end{array}$ & & Died \\
\hline $\begin{array}{l}\text { Ma } \\
\text { et al. }{ }^{14)}\end{array}$ & 2015 & 62 & M & & & $(-)$ & $(+)$ & $(+)$ & $(+)$ & $5 \mathrm{~m}$ & WM & & SSS & $\begin{array}{l}\text { Labbe, } \\
\text { Trolard }\end{array}$ & $(-)$ & TAE, SIR & Onyx & Normalized \\
\hline
\end{tabular}




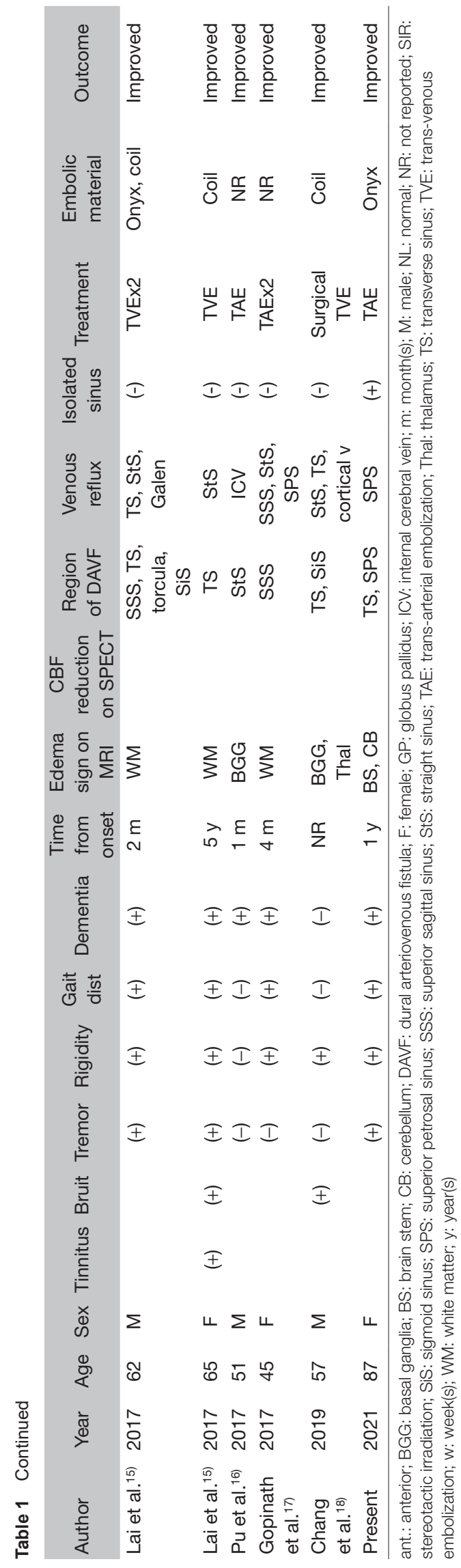

and sigmoid sinus $(\mathrm{n}=7)$ (Table 1). The edematous changes associated with venous congestion on MRI are often observed in the basal ganglia or white matter of the cerebral hemisphere. In most of such cases $(n=9)$, the venous reflux from the straight sinus to the internal cerebral veins or deep venous system caused the venous congestion of the basal ganglia or white matter. However, these changes are not observed on MRI in some cases, ${ }^{1,4,6,11,12)}$ and it is more difficult to diagnose DAVF in such cases. Even in cases with no abnormality on MRI, reduced cerebral blood flow is often observed in singlephoton emission $\mathrm{CT}^{1,11)}$; thus, the basic etiology of this disease is decreased blood flow due to venous congestion. In the present case, edematous changes were observed in the midbrain, pons, and cerebellar peduncle. Such findings have not been described in previous reports of parkinsonian patients with DAVF. It is reported that bilateral pedunculopontine nuclei infarction causes frozen gait, which is one of the symptoms of parkinsonism. ${ }^{18)}$ From these findings, it is considered that a disorder of the substantia nigrastriatum system may be a cause of parkinsonism. In the present case, a preexisting lacunar infarction was the only finding on MRI when the patient was diagnosed with Parkinson's disease one year earlier and the interval from the onset of symptoms to diagnosis was nearly one year. Edema may not have occurred in the brainstem or cerebellar peduncle due to the low flow of the AV shunt of DAVF at the time of onset. It is speculated that the edema of the brainstem occurred as the AV shunt flow of DAVF intensified and the parkinsonism was probably caused by the disfunction in the bilateral pedunculopontine nucleus. The treatment options for DAVF include endovascular treatment, direct surgery, and radiation therapy. The standard treatment of sinus-type DAVF is transvenous embolization (TVE). In the isolated sinus-type DAVF, like the present case, there are two treatment options: 1) outflow occlusion by open surgery and 2) TAE with a liquid embolic material, penetrating from the shunt point to the venous outflow, as the same concept of the surgical technique. ${ }^{19,20)}$ Of these 21 reported cases, all the patients with isolated sinus were treated with TAE $(n=5)$. The patients without isolated sinus were treated with TAE alone $(\mathrm{n}=6)$, with TAE and TVE $(n=2)$, and with TVE alone $(n=5)$. Coils are used as an embolic material in TVE, while a liquid embolic material is used in TAE. Recently, Onyx has been widely used as a liquid embolic material. It is a non-adhesive liquid agent comprising ethylene vinyl alcohol copolymer dissolved in dimethyl sulfoxide (DMSO) and suspended 
Tominaga $A$, et al.

micronized tantalum powder to provide contrast for visualization under fluoroscopy. Onyx can penetrate from the shunt to the venous side by slow injection. In most cases, it easily migrates into other feeders via the arterial network and finally gets into the venous or sinus side. Treatment under general anesthesia is recommended in the use of Onyx because its injection is associated with much pain. We treated the present case under local anesthesia because we thought the general anesthesia might cause postoperative delayed arousal since the patient had akinesia. In many reported cases, parkinsonism improved within a few days to a few weeks. In the present case, rapid improvement was observed within approximately one week.

\section{Conclusion}

DAVF-derived parkinsonism is a rare disease; however, it is treatable with endovascular procedures. When a patient has parkinsonism with dementia, we need to consider DAVF-derived parkinsonism as a differential diagnosis. Even if no abnormality is found in the initial MRI in patients with parkinsonism, DAVF may be diagnosed by follow-up MRI. Therefore, repeated MRI examination should be done in the parkinsonian patient with atypical clinical courses.

\section{Disclosure Statement}

The authors declare no conflicts of interest in association with the present study.

\section{References}

1) Chaichana KL, Coon AL, Tamargo RJ, et al. Dural arteriovenous fistulas: epidemiology and clinical presentation. Neurosurg Clin N Am 2012; 23: 7-13.

2) Oh JT, Chung SY, Lanzino G, et al. Intracranial dural arteriovenous fistulas: clinical characteristics and management based on location and hemodynamics. J Cerebrovasc Endovasc Neurosurg 2012; 14: 192-202.

3) Matsuda $S$, Waragai $M$, Shinotoh $H$, et al. Intracranial dural arteriovenous fistula (DAVF) presenting progressive dementia and parkinsonism. J Neurol Sci 1999; 165: 43-47.

4) Hamada Y, Yamakawa Y, Fukui M. A case of dural arteriovenous fistula in the anterior cranial fossa presenting frozen gait. Jpn J Neurosurg 2003; 12: 798-802. [in Japanese]

5) Lee PH, Lee JS, Shin DH, et al. Parkinsonism as an initial manifestation of dural arteriovenous fistula. Eur $J$ Neurol 2005; 12: 403-406.
6) Kajitani M, Yagura H, Kawahara M, et al. Treatable fluctuating parkinsonism and dementia in a patient with a dural arteriovenous fistula. Mov Disord 2007; 22: 437-439.

7) Miura S, Noda K, Shiramizu N, et al. Parkinsonism and ataxia associated with an intracranial dural arteriovenous fistula presenting with hyperintense basal ganglia in T1-weighted MRI. J Clin Neurosci 2009; 16: 341-343.

8) Nogueira RG, Baccin CE, Rabinov JD, et al. Reversible parkinsonism after treatment of dural arteriovenous fistula. J Neuroimaging 2009; 19: 183-184.

9) Netravathi M, Pal PK, Bharath RD, et al. Intracranial dural arteriovenous fistula presenting as parkinsonism and cognitive dysfunction. J Clin Neurosci 2011; 18: 138-140.

10) Shahar T, Gadoth A, Nossek E, et al. Reversible freezing of gait caused by dural arteriovenous fistula and congestion of the globus pallidus. Mov Disord 2012; 27: 1690-1693.

11) Hattori $T$, Takeuchi $T$, Kabeya R, et al. Transverse-sigmoid sinus dural arteriovenous fistula presenting with parkinsonism. Neurol Med Chir (Tokyo) 2013; 53: 224-227.

12) Fujii H, Nagano $Y$, Hosomi N, et al. Dural arteriovenous fistula presenting with progressive dementia and parkinsonism. BMJ Case Rep 2014; doi: 10.1136/bcr-2014-203921.

13) Luo Y, Qi J, Cen Z, et al. Two cases of dural arteriovenous fistula presenting with parkinsonism and progressive cognitive dysfunction. J Neurol Sci 2014; 343: 211-214.

14) Ma C, Lu Q, Shi W, et al. Diagnosis and treatment of a dural arteriovenous fistula presenting with progressive parkinsonism and dementia: a case report and literature review. Exp Ther Med 2015; 9: 523-526.

15) Lai J, Heran MKS, Stoessl AJ, et al. Reversible parkinsonism and rapidly progressive dementia due to dural arteriovenous fistula: case series and literature review. Mov Disord Clin Pract 2017; 4: 607-611.

16) Pu J, Si X, Ye R, et al. Straight sinus dural arteriovenous fistula presenting with reversible parkinsonism: a case report and literature review. Medicine (Baltimore) 2017; 96: e9005.

17) Gopinath $M$, Nagesh $C$, Santhosh $K$, et al. Dementia and parkinsonism--a rare presentation of intracranial dural arteriovenous fistulae. Neurointervention 2017; 12: 125-129.

18) Chang CW, Hung HC, Tsai JI, et al. Dural arteriovenous fistula with sinus thrombosis and venous reflux presenting as parkinsonism: a case report. Neurologist 2019; 24: 132-135.

19) Nelson PK, Russell SM, Woo HH, et al. Use of a wedged microcatheter for curative transarterial embolization of complex intracranial dural arteriovenous fistulas: indications, endovascular technique, and outcome in 21 patients. J Neurosurg 2003; 98: 498-506.

20) Carlson AP, Taylor CL, Yonas H. Treatment of dural arteriovenous fistula using ethylene vinyl alcohol (onyx) arterial embolization as the primary modality: short-term results. $J$ Neurosurg 2007; 107: 1120-1125. 